\title{
COMMENTARY
}

\section{The Contribution of Medical Care to Mortality Decline: McKeown Revisited}

\author{
Johan P. Mackenbach \\ DEPARTMENT OF PUBLIC HEALTH, ERASMUS UNIVERSITY ROTTERDAM, ROTTERDAM, THE NETHERLANDS
}

\section{INTRODUCTION}

In St. James's Church (Sussex Gardens, London, U.K.) there is a stained glass window, which shows Sir Alexander Fleming at work in his laboratory. Fleming's laboratory was located in the vicinity of this church, and it was there that he discovered the bactericidal effects of penicillin. This church window perhaps is an illustration of the almost religious role of medicine in our modern society. In any case, it shows a deep respect for the advances of medicine, which in the popular opinion has become a master of life and death.

The contrast between this popular opinion and the current scientific view of the effects of medical cate on the health of populations is enormous. This is due to a large extent to the work of the late Thomas Mckeown. His famous analyses of the history of mortality in England and Wales, which originally appeared in a number of journal articles, were summarized in 1976 in two books, of which The Role of Medicine-Dream, Mirage or Nemesis has been very influential $[1,2]$. In this book he showed that the decline in mortality since the middle of the nineteenth century was the result mainly of a decline in mortality from infectious diseases. The latter decline for the most part antedated the introduction of specific medical therapies, including Fleming's penicillin.

From these analyses McKeown has drawn two conclusions, which both have generally been accepted by the scientific community, particularly by epidemiologists. The first was that medical care has not made a substantial contribution to mortality decline since the middle of the nineteenth century. The second, and more far-reaching, conclusion was that today's health problems are also more likely to be controlled hy changing the environment than by medical care.

Since the publication of McKeown's findings important criticisms have been voiced, which together with more recent evidence suggest that some modifications of these conclusions may be necessary. The objective of this article is to review McKeown's analysis and the more recent evidence, and to investigate whether the scientific opinion should or should not be reshifted a bit toward the popular opinion. Throughout this article data from The Netherlands, a country with abundant data of relatively high quality, are used as illustrations.

\footnotetext{
Address reprint requests to: Johan P. Mackenhach, Department of Public Health, Erasmus University Rotterdam, P.O. Box 1738, 3000 DR Rotterdam The Netherlands.

An earlier version of this paper was presented at the Honda Foundation Conference on "The determinants of health: prosperity, health and wellbeing, Toronto, October 16-18, 1993."

Accepted for publication on 1 April 1996.
}

\section{THE PATTERN OF MORTALITY DECLINE AND MCKEOWN'S ARGUMENTS ABOUT THE ROLE OF MEDICINE}

In all western countries life expectancy at birth has increased tremendously since the middle of the nineteenth century. This increase in life expectancy was caused by an unprecedented decline in mortality, which in the pre-McKeown era was generally ascribed to improvements in medical care [3]. McKeown's arguments against any important effects of medical care on this decline in mortality have the structure of a syllogism:

the decline in mortality can be attributed to a decline in infectious disease mortality;

no effective medical interventions were available against infectious diseases before the middle of the twentieth century;

thus, most of the decline in mortality cannot be attributed to the introduction of effective medical interventions.

The first part of McKeown's syllogism was supported by the results from an impressive analysis of changes in cause-specific mortality in England and Wales between 1848/1854 and 1971. In this analysis it was shown that $74 \%$ of the reduction in total mortality was due to a decline in mortality from conditions attributahle to microorganisms. Among the latter, airborne infections such as respiratory tuberculosis and pneumonia made the largest contribution $[1,2]$.

Largely similar patterns of cause-specific mortality decline have been observed in other western countries [4-7]. Table 1 illustrates this for The Netherlands, where the earliest available data on mortality by cause of death apply to the years $1875 / 1879$. A number of specific infectious diseases accounted for $47 \%$ of the decline in mortality between 1875/1879 and 1970 among men, and $45 \%$ of the decline in mortality among women. Airborne infections form the subgroup with the largest contribution. In addition to these specific infectious diseases, some other causes of death that are distinguished in Table 1 are also of an infectious nature. Convulsions is an important example: deaths from convulsions mostly occurred among febrile children. Puerperal fever, of course, also is an infectious disease. Finally, it is quite likely that a part of the mortality decline for the "other" causes, which included ill-defined conditions, was actually due to infectious diseases. The 45 to $47 \%$ of Table 1 should therefore be raised by some 20 to $30 \%$ in order to arrive at a more realistic estimate-an estimate that is also closer to that of McKeown $[6,7]$.

The second part of McKeown's syllogism was supported by a detailed analysis of the moment at which effective medical interventions for each infectious disease became available. In McKeown's view, the advent of the sulfonamides and antibiotics in the $1930 \mathrm{~s}$ and 1940 s marked this point in time for a large majority of infectious 
TABLE 1. The contribution of specific causes of death to mortality decline between $1875 / 1879$ and 1970 in The Neth. erlands ${ }^{a}$

\begin{tabular}{lrr}
\hline & $\begin{array}{c}\text { Percentage } \\
\text { contribution } \\
\text { to all-cause } \\
\text { mortality } \\
\text { decline }\end{array}$ \\
\cline { 2 - 3 } Cause of death & Men & Women $^{b}$ \\
\hline Infectious diseases & 47 & 45 \\
Diarrheal diseases & 11 & 10 \\
Smallpox & 0 & 0 \\
Scarlet fever and measles & 2 & 2 \\
Pertussis and diphtheria & 3 & 3 \\
Respiratory tuberculosis & 13 & 14 \\
Pneumonia/acute bronchiris/influenza & 12 & 10 \\
Malaria & 1 & 1 \\
Other & 6 & 5 \\
Mental diseases/diseases of nervous system & 13 & 11 \\
Convulsions & 7 & 6 \\
Other & 6 & 5 \\
Diseases of respiratory system & 8 & 8 \\
Diseases of digestive system & 3 & 3 \\
Diseases of pregnancy/childbirth/puerperium & na & 2 \\
Puerperal fever & na & 1 \\
Other & na & 1 \\
Congenital diseases & 0 & 0 \\
Perinatal conditions & 4 & 4 \\
All other diseases & 24 & 27 \\
Total & 100 & 100 \\
\hline Adant for & &
\end{tabular}

"Adapted from Ref. 7.

${ }^{b}$ The percentage contribution of each cause of death to mortality decline was determined by subtracting the age-standardized mortality rate for that cause in 1970 from the age-standardized rate in 1875/1879. The difference was divided by the total mortality decline over the same period, and multiplied by 100 .

'na, Not applicable.

diseases. McKeown has published a number of impressive graphs, in which it is shown that the decline in mortality from a specific infectious disease had already largely occurred when these drugs became available. There was only a small number of exceptions, for example diphtheria (antitoxin, late ninetecnth century) and syphilis (salvarsan, early twentieth century) $[1,2]$. For some infectious diseases, immunization was a more important breakthrough than antibiotics, but most forms of immunization were introduced only in the $1940 \mathrm{~s}$ and the 1950s. Smallpox was the only important exception $[8,9]$.

In view of the importance of the timing of the decline in infectious disease mortality for McKeown's arguments, Table 2 presents some quantitative data for The Netherlands. For many infectious diseases mortality decline was concentrated in the period 1903 to 1930. Note that for smallpox and malaria, which had already declined as causes of death before 1875 , the (remaining part of the) decline occurred almost completely before 1903 . Only $19 \%$ of the decline in mortality from infectious diseases occurred in the period 1930 to 1950 , and 4 to $5 \%$ in the period 1950 to 1970 [6].

After his account of the contribution of medical care, McKeown turned to a consideration of other possible explanations of the decline in infectious disease mortality. He first discussed the pussibility of a spontaneous change in the relation between infectious agents and human hosts. There is some evidence that a decreasing viru- lence of the streptococcus has played a role in the decline of scarlet fever mortality, but this mechanism is unlikely to have been important for the decline in infectious disease mortality in general.

By exclusion, McKeown considers a third possibility, a favorable change in the environment, as the most plausible explanation for the decline in infectious disease mortality. Mckeown considered two specific contributions to these changes: hygienic measures and rising standards of living. In his choice for the latter as the most important factor in mortality decline, the distinction between airborne and water- and foodborne infectious diseases played an important role. The classical hygienic measures from the second half of the nineteenth century (safe drinking water, sewage disposal) are not likely to have affected the airborne diseases, which made the largest contribution to mortality decline. Furthermore, McKeown argues that these hygienic measures cannot explain the start of the mortality decline, because they were effective only after ca. 1880 , when mortality decline was already well underway.

After having discarded all these other possibilities McKeown concludes that a rise in living standards, particularly the associated improvements in nutritional status, have probably been the most important factor in mortality decline. It is important to note that no direct evidence in support of this conclusion is given by Mckeown-he cites only some circumstantial evidence suggesting improvements in food supply $[1,2]$.

\section{THE DIRECT EFFECTS OF MEDICAL CARE ON THE HISTORICAL DEVELOPMENT OF MORTALITY: OTHER VIEWS}

This section considers the criticisms of McKeown's conclusions regarding the direct effects of medical care on mortality.

Although the first antibiotics, as McKeown showed, arrived only when the largest part of the decline in mortality from infectious diseases had already taken place, a quantitative analysis of the associated changes in mortality does suggest that the impact as such was substantial. In The Netherlands, when one compares the trend in mortality from infectious diseases before the introduction of antibiotics with that in a period after the introduction of these drugs, one sees that for almost all infectious diseases mortality decline accelerated. Table 3 shows that this acceleration is particularly impressive for bacillary dysentery, scarlet fever, tuberculosis, syphilis, erysipelas, rheumatic fever, and puerperal fever. Whereas mortality from all infectious diseases together declined $4 \%$ per year before the introduction of antibiotics, it declined $10 \%$ per year after the introduction. In the analysis on which Table 3 is based, it was shown that for many infectious diseases there was not only a more permanent acceleration of mortality decline, but also an instantaneous, stepwise decrease in mortality coinciding with the introduction of antibiotics [10].

Of course, although the observed changes in mortality are roughly coinciding with the introduction of antibiotics, a causal relationship is not necessarily implied. At least two other explanations should be considered: changes in the rate of improvement of living standards, and changes in the intensity and effectiveness of public health programs. However, time series data on the availability of food, on housing conditions, and on other correlates of living standards do not show accelerations of improvements atter World War II in 'T he Netherlands. The other alternative explanation, public health prograns, can apply only to tuberculosis. Pasteurization of milk was introduced in 1940 in The Netherlands, reducing the incidence of nontespiratory tuberculosis. Mass radiography was introduced in 
TABLE 2. The percentage distribution of the decline in mortality from infectious diseases in The Netherlands over four subperiods, $1875 / 1879-1970^{a}$

\begin{tabular}{|c|c|c|c|c|c|c|c|}
\hline \multirow[b]{2}{*}{ Disease } & \multirow[b]{2}{*}{ Sex } & \multirow{2}{*}{$\begin{array}{c}\text { Mortality } \\
\text { decline } \\
1875 / 1879 \\
-1970^{b}\end{array}$} & \multicolumn{5}{|c|}{ Percentage distribution } \\
\hline & & & $\begin{array}{c}1875 / 1879 \\
-1970 \\
\end{array}$ & $\begin{array}{c}1875 / 1879 \\
-1903 \\
\end{array}$ & $1903-1930$ & $1930-1950$ & $1950-1970$ \\
\hline \multirow[t]{2}{*}{ Diarrheal diseases } & $\mathrm{m}$ & 1.89 & 100 & 20 & 71 & 8 & 1 \\
\hline & $f$ & 1.68 & 100 & 29 & 64 & 6 & 1 \\
\hline \multirow{2}{*}{ Smallpox } & $\mathrm{m}$ & 0.02 & 100 & 100 & 0 & 0 & 0 \\
\hline & $f$ & 0.02 & 100 & 50 & 50 & 0 & 0 \\
\hline \multirow[t]{2}{*}{ Scarlet fever and measles } & $\mathrm{m}$ & 0.30 & 100 & 23 & 50 & 23 & 3 \\
\hline & $f$ & 0.28 & 100 & 21 & 54 & 21 & 4 \\
\hline \multirow{2}{*}{ Pertussis and diphtheria } & $\mathrm{m}$ & 0.51 & 100 & 53 & 22 & 18 & 8 \\
\hline & $t$ & 0.53 & 100 & 51 & 23 & 20 & 7 \\
\hline \multirow[t]{2}{*}{ Respiratory tuberculosis } & $\mathrm{m}$ & 2.23 & 100 & 36 & 41 & 16 & 7 \\
\hline & $\mathrm{f}$ & 2.34 & 100 & 44 & 31 & 21 & 4 \\
\hline \multirow{2}{*}{$\begin{array}{l}\text { Pneumonia/acute bronchitis/ } \\
\text { influenza }\end{array}$} & $\mathrm{m}$ & 2.14 & 100 & 13 & 53 & 32 & 3 \\
\hline & $\mathrm{f}$ & 1.66 & 100 & 2 & 60 & 31 & 7 \\
\hline \multirow[t]{2}{*}{ Malaria } & $\mathrm{m}$ & 0.17 & 100 & 100 & 0 & 0 & 0 \\
\hline & $\mathrm{f}$ & 0.17 & 100 & 94 & 6 & 0 & 0 \\
\hline \multirow[t]{2}{*}{ Other infectious discases } & $\mathrm{m}$ & 1.00 & 100 & 28 & 41 & 22 & 9 \\
\hline & $f$ & 0.86 & 100 & 33 & 36 & 23 & 9 \\
\hline \multirow[t]{2}{*}{ Subtotal infectious diseases } & $\mathrm{m}$ & 8.27 & 100 & 27 & 49 & 19 & 4 \\
\hline & f & 7.54 & 100 & 31 & 45 & 19 & 5 \\
\hline \multirow{2}{*}{$\begin{array}{l}\text { Total mortality, all causes } \\
\text { of death }\end{array}$} & $\mathrm{m}$ & 15.14 & 100 & 40 & 45 & 15 & 0 \\
\hline & f & 15.79 & 100 & 40 & 33 & 17 & 11 \\
\hline
\end{tabular}

"Adapted from Ref. 6.

"Difference hetween the age-standardized death rates (in deaths per 1000 person-years) of $1875 / 1879$ and 1970 .

1949, and the combined effects of early detection and effective treatment may have caused a considerable acceleration in tuberculosis incidence decline. Nevertheless, in the late 1940s and the early 1950s mortality from tuberculosis declined much faster than incidence in The Netherlands, suggesting that case fatality was also declining considerably, possibly due to the introduction of streptomycin and other antibiotics [10].

Although antibiotics were certainly a very important factor in the history of the medical treatment of infectious diseases, it is not as certain as McKeown would like us to believe that they were the first effective medical intervention against infectious diseases. McKeown himself mentions a number of quantitatively unimportant infectious diseases for which other types of effective interventions were available before the middle of the twentieth century. Much more important is the question concerning whether improvements in medical care may have contributed to the decline in tuberculosis mortality [11]. Unfortunately, evidence on the effectiveness of isolation of patients in sanatoria and on the effectiveness of contact tracing and dietary advice is lacking. To assume that all these interventions have had no effect at all is, of course, not a rational response to this lack of evidence. It is quite likely that these interventions did do some good-we just do not know how much.

Because in this discussion quantification of effects is essential, it seemed useful to perform a sensitivity analysis of the direct contribution of medical care to the decline of mortality in The Netherlands, combining the data that were presented in Tables 1 and 2 with a number of assumptions on the effect of medical care on mortality from specific conditions (Table 4). Forty-six percent of the decline in toral mortality was due to a number of specific infectious diseases; only a small part occurred after the introduction of antibiotics, which has arbitrarily been fixed in 1946 (14\%-this figure was estimated on the basis of more detailed data than were presented in Table 2). Table 3 showed that the rate of mortality decline for infectious diseases more than doubled after the introduction of antibiotics. How much of the decline after introduction of antibiotics was due to introduction of these drugs is difficult to say. It may be $60 \%$ (if one assumes that the prewar trends would have continued unchanged in the absence of antibiotics), but it could also be more (if one assumes that the improvements in living standards had already reached their maximum effect before the war) or less. In Table 4 it is assumed that the lower limit of the contribution of medical care to the decline of infectious disease mortality after 1946 is $25 \%$, and the upper limit $75 \%$. If we combine all these figures, it would appear that the lower limit for the contribution of medical care to decline in total mortality between $1875 / 1879$ and 1970 in The Netherlands, on the hasis of the effects of antihiotics on sperific infectious diseases, is $1.6 \%$, and the upper limit $4.8 \%$.

This is, however, not the only direct contribution of medical care to the decline in mortality. Effects of interventions that were already available before the advent of antibiotics may have contributed to the decline in mortality from specific infectious diseases before 1946. Also, some infectious diseases are probably hidden in other causes of death. Furthermorc, the effects of medical care were not limited to the infectious diseases. Two other categories of causes of death for which medical care has probably contributed to the decline in mortality are diseases of the digestive system (improvements in surgery starting around 1930 have probably contributed to the decline in mortality from appendicitis [12], cholecystitis [13], intestinal obstruction [14], etc.) and perinatal conditions (improvements in antenatal and perinatal care have probably contributed to a mortality decline after about 1930 [15]). Combining all these effects, one arrives at an estimate of between $4.7 \%$ (lower limit) and $18.5 \%$ (upper 
TABLE 3. Trends in age- and sex-adjusted mortality from infectious diseases before the introduction of antibiotics (19211939) and after the introduction of antibiotics $(1947-1968)^{a}$

\begin{tabular}{lcc}
\hline & \multicolumn{2}{c}{$\begin{array}{c}\text { Annual percentage } \\
\text { change in mortality }\end{array}$} \\
\cline { 2 - 3 } Disease & $\mathbf{1 9 2 1 - 1 9 3 9}$ & $\mathbf{1 9 4 7 - 1 9 6 8}$ \\
\hline Bacillary dysentery & +5 & -19 \\
Typhoid fever & -10 & -2 \\
Scarlet fever & -3 & -13 \\
Measles & -8 & -9 \\
Tuberculosis & -6 & -16 \\
Pneumonia & -4 & -5 \\
Acute bronchitis & -7 & -9 \\
Influenza & -1 & -5 \\
Syphilis & -1 & -9 \\
Erysipelas & -2 & -11 \\
Septicemia & -6 & -4 \\
Meningococcal meningitis & -1 & -6 \\
Nonmeningococcal meningitis & -8 & -4 \\
Otitis media & +5 & -8 \\
Upper respiratory infections & +3 & -5 \\
Cystitis & -4 & -6 \\
Skin infections & -3 & -7 \\
Osteomyelitis & -1 & -5 \\
Rheumatic fever & -0 & -16 \\
Puerperal fever & -1 & -11 \\
All infectious diseases & -4 & -10 \\
All other diseases & -1 & 0 \\
Tutal mortality & 2 & 1 \\
\hline
\end{tabular}

"Adapted from Ref. 10.

"Estimated on the basis of a Poisson regression analysis, in which the mortality rate was modeled as a function of calendar year and the number of person-years at risk hy age and sex. The period 1940-1946 was left out of the analysis because of the effects of World War II.

limit) for the direct contribution of medical care to decline of mortality between 1875/1879 and 1970 in The Netherlands.

\section{INDIRECT EFFECTS OF MEDICAL CARE ON THE HISTORICAL DEVELOPMENT OF MORTALITY}

The second line of criticism against McKeown's conclusions deals with the indirect effects of medical care on mortality decline, through the contributions of doctors to sanitary reform and to behavioral changes in the population.

After McKeown had discarded the possible contributions of medical care to mortality decline, he turned to other explanations for the decline in mortality from infectious diseases. Unfortunately, as he himself already noticed, his argument at this stage resembles that of Sherlock Holmes, who is reported to have said to Watson: "When we have eliminated the impossible, whatever remains, however improbable, must be the truth" [2].

McKeown's conclusion about the predominant role of the rise in living standards, particularly improvements in nutritional status, in the explanation of mortality decline is drawn by exclusion. The evidence supporting this remaining possibility was judged much less severely than that concerning the explanations that had been rejected before. Furthermore, such a conclusion drawn by exclusion will be valid only if all possible alternatives have been considered. That is not quite the case: sanitary reform may have been more important than McKeown thought, and he has also practically overlooked a completely different class of explanations, those related to cultural or behavioral changes.

McKeown's argument against a substantial contribution of sanitary reform was twofold. He thought it was unlikely that sanitary reform had contributed to a decline in mortality from airborne diseases, and the decline in mortality from food-and waterborne diseases started before hygienic measures had been implemented on a large scale. Both reasonings can be criticized. Safe drinking water supplies and sewage disposal systems were not the only hygienic measures that were implemented by the sanitary reformers. Improvements in working and housing conditions were other important parts of their program. It is not difficult to see that better ventilation of working places and less crowded houses can have contributed to the decline in mortality from airborne diseases [16]. With regard to the sccond rcasoning it can bc argucd that McKcown's cmphasis on the starting point of the decline of mortality from food-and waterborne diseases distracted from the fact that the largest part of the decline in mortality from these conditions occurred in the period between ca. 1900 and ca. 1930 (Table 3). That is precisely the period in which the benefits of safe drinking water supplies and sewage disposal systems are to be expected [17-20].

Of course, the credit for these reforms mainly belongs to the public health sector. But many of these sanitary reformers were actually medical doctors, both in The Netherlands and in many other Western European countries. They applied medical knowledge, gained inside the medical care system, in their epidemiological studies and in their proposals for reform. It is as difficult to imagine these reforms without the medical knowledge contributed by these doctors, as it is to imagine them without the expertise and skills of engineers. One can therefore argue that a small part of the mortality decline that was caused by the sanitary reform measures, actually is an indirect effect of medical care on mortality.

Even if one rejects conscious action on the part of medical care or the public health system as a main factor in the decline of mortality, it is not evident that the only autonomous changes were those directly flowing from the rise in living standards. Obviously, the rise in living standards in its turn needs an explanation. How could countries in Western Europe suddenly escape from the old economic order, and start an unprecedented rise in economic output? A discussion of this topic is outside the scope of this article, but one plausible explanation is that cultural changes, in the broadest sense of the word, preceded the changes in cconomic activity [21]. In The Netherlands around 1850 a change in mentality occurred that affected many sectors of society: the educational system started its expansion, all kinds of societies promoting the public good were founded, and investments in new economic enterprises were also made [22]. These cultural changes may act as a confounder of the association that is observed between living standards and decline in mortality.

Two important changes in determinants of mortality that are clearly related to these cultural changes are improvements in personal care, particularly personal hygiene, and the application of birth control. Improvements in personal hygiene may have contributed to the decline in mortality from many infectious diseases, such as typhus [23] and water- and foodborne diseases. Birth control will have contributed to an improvement of the health status of mothers, and also to an improvement of the health of children [24].

Were these cultural changes completely external factors from the point of view of medical care? No, not entirely. Many private societies propagated modern behavior among the population. This propaganda was also part of the work of the welfare clinics for infants and 
TABLE 4. An estimate of the direct contribution of medical care to the decline in mortality between $1875 / 1879$ and 1970 in The Netherlands

Steps in calculation

Description

1. a. Contribution of specific infectious diseases to decline in total mortality $1875 / 1879-1970$

b. Of which after 1946

c. Of which due to medical care

d. $1 \mathrm{a} \times 1 \mathrm{~b} \times 1 \mathrm{c}$

2. a. Contribution of specific infectious diseases to decline in total mortality $1875 / 1879-1970$

b. Of which between 1900 and 1946

c. Of which due to medical care

d. $2 \mathrm{a} \times 2 \mathrm{~b} \times 2 \mathrm{c}$

3. a. $1 d+2 d$

b. Contribution of infectious diseases hidden in other cause-ofdeath groups to decline in total mortality 1875/1879-1970

c. $(1 a+3 b) / 1 a$

d. $3 \mathrm{a} \times 3 \mathrm{c}$

4. a. Contribution of diseases of digestive system to decline in total mortality 1875/1879-1970

b. Of which after 1930

c. Of which due to medical care

d. $4 \mathrm{a} \times 4 \mathrm{~b} \times 4 \mathrm{c}$

5. a. Contribution of perinatal conditions to decline in total mortality $1875 / 1879-1970$

h. Of which after 1930

c. Of which due to medical care

d. $5 \mathrm{a} \times 5 \mathrm{~b} \times 5 \mathrm{c}$

6. Total contribution of medical care to decline in total mortality

$1875 / 1879-1970(3 \mathrm{~d}+4 \mathrm{~d}+5 \mathrm{~d})$
$25-75$

Intermediate

results

(\%)

46

$25-75$

1.6

46
57

57

$5-20$

$2.9-10.0$

1.3

20-30

1.4-1.7

4.1

17.0

3

23

$30-70$

0.2

4

35

30-70

0.4

1.0

4.7 toddlers, which were founded after the turn of the century. Again, medical doctors have played an outstanding role in these activities. They wrote treatises on infant care and on personal hygiene, and their medical expertise was diffused in this way thoughout the population $[18,25]$.

\section{THE CONTEMPORANEOUS EFFECTS OF MEDICAL CARE ON MORTALITY}

The third line of criticism deals with McKeown's statement that the historical evidence suggests that today's health problems are also more likely to be controlled by changing the environment than by improving medical care. However, from the fact that environmental change has made a larger contribution to mortality decline than medical interventions in a certain historical period, it does not necessarily follow that environmental changes are more effective means of intervention under current circumstances too [26].

In fact, a universal comparison of the effectiveness of environmental change and medical care is not possible with McKeown's historical data. "Environmental measures were tested when mortality was high, antibiotics when the mortality was low; environmental measures were tested alone, antibiotics against the hackground of environmental change. . . English archers at Agincourt did better than English riflemen on the Somme, and it does not follow that archers have greater military potential" [27].
One could further argue that the comparison between the changes induced by the introduction of antibiotics and other modern forms of medical care, and the changes that occurred in a very long period of time before that, does injustice to the advances of medical care. For contemporary patients only contemporary effects count, and it may therefore be more appropriate to compare the mortality effects of medical care with those of other influences operating in the same recent period [28].

The hasis for such a comparison can he found in a number of publications in which mortality from conditions that have become amenable to medical intervention is analyzed. These publications, which have dealt with the experience in many different countries, employ Rutstein's lists of "unnecessary untimely mortality"- - selections of conditions in which death can be avoided by adequate preventive or therapeutic intervention [29]. Most of these conditions have become amenable to medical intervention only in the last 40 years. Rapid declines in mortality from the amenahle causes were observed in all countries that have heen studied [30].

This is illustrated by Table 5, which provides estimates of the effects of these mortality declines on average life expectancy at birth in The Netherlands. Owing to these declines in mortality, life expectancy at birth increased by almost 3 years for men, and by almost 4 years for women. The difference hetween men and women can almost entirely be explained by the greater importance of hypertensive and cerebrovascular disease among women. Of course, it is too 
TABLE 5. The effects of mortality reductions for conditions that have become amenable to medical intervention on average life expectancy at birth in The Netherlands 1950/1954$1980 / 1984^{a}$

Life expectancy

gains (in years)

Men Women

Gains ${ }^{h}$ due to reductions in mortality from:

Infectious diseases

$0.94 \quad 1.13$

Certain surgical conditions ${ }^{d}$

0.36

Maternal and perinatal conditions

0.12

0.25

Hypertensive and cerebrovascular disease

0.43

0.63

Other amenable conditions

All amenable conditions

0.58

1.32

3.95

Observed gain ${ }^{g}$

1.91

5.86

"Adapted from Ref. 32

"Calculated as the difference between actual life expectancy at birth in $1980 / 1984$ and the life expectancy which would have been attained if the mortality rates for the selected conditions had remained at the level of 1950/ 1954.

Tuberculosis, pneumonia/influenza, septicemia, infections of the urinary system, other infectious diseases.

"Peptic ulcer, appendicitis, cholelithiasis/-cystitis, abdominal hernia, ileus without hernia, benign prostatic hyperplasia.

"Discases of the thyroid, diabetes mellitus ( $<25$ years), pernicious ancmia, other anemias, congenital digestive anomalies, congenital cardiovascular anomalies, theumatic heart disease, nephritis and nephrosis, cancer of lip and skin, cancer of kidney $(<15$ years), morhus Hodgkin, cancer of testis, leukemia ( $<15$ years), cancer of cervix uteri.

'Sum of the above.

:Calculated as the difference between the average life expectancy at hirth in 1980/1984 and the average life expectancy at birth in 1950/1954

generous to attribute all the decline in mortality from these conditions (and the associated increase in life expectancy) to improvements in medical care. Probably only a part was due to these improvements, but this may at least in part be compensated for by the fact that medical interventions also made an impact on causes of death that were not included in these selections, such as ischemic heart disease [31].

In any case, if one compares these gains in life expectancy due to reductions in mortality from amenable conditions, with the observed gains in life expectancy in the same period, it is evident that something remarkable has happened. Among men, the actual gain in life expectancy was less than the gain that could have been expected on the basis of the reductions in mortality from amenable conditions. This implies that mortality from nonamenable conditions has increased over the same period. Among women, the observed gain in life expectancy was almost 6 years, of which twothirds appeared to have been due to a decline in mortality from amenable conditions. Whatever the exact contribution of medical care to the decline in mortality from amenable conditions, the contribution to the development of overall mortality and life expectancy is likely to have been substantial relative to that of other contemporary determinants [32].

\section{CONCLUSIONS}

The evidence presented in this article suggests that:

The direct contribution of medical care to historical mortality decline was certainly not negligible, and perhaps even sizable
Medical care has also made indirect contributions to historical mortality decline, by transfer of knowledge from the medical profession to sanitary reformers and the general public

Medical care is likely not to have been a less important factor in recent mortality decline than other contemporary determinants

Where does this leave us with regard to McKeown's two main conclusions and the gap between the two conventional wisdoms (one popular, one scientific) on the effectiveness of medical care? First of all, it is important to emphasize the limitations of the analyses reviewed in this article. As so many other papers before, including those of McKeown, only the effects of medical care on mortality were considered. Owing to an almost complete lack of data on time trends in morbidity, the effects of medical care on morbidity are even more uncertain that those on mortality. Second, although the evidence on mortality is much less sparse, it is still far from dense. Patterns of mortality decline have been described in detail for several countries, but estimates of the contribution of medical care to mortality decline are largely based on informed guesses. This also applies to the contribution of other factors, such as hygienic measures and rising living standards-actually, there is even less firm evidence on these competing factors, so that a valid comparison with the effects of medical care is difficult.

Given these uncertainties it is perhaps wise to refrain from any far-reaching conclusions. The role of medicine may not have been, or now be, as modest as McKeown liked us to believe, and it is not clear at all that the conviction among many scientists on the relative inferiority of medical care as a determinant of mortality change has more scientific backing than the popular wisdom of the role of medicine reflected in church windows.

\section{References}

1. Mckeown ThF. The Role of Medicine-Dream, Mirage or Nemesis? London: Nuffield Provincial I Lospitals Trust; 1976.

2. McKeown ThF. The Modern Rise of Population. London: Edward Arnold; 1976.

3. Griffiths GT. Population Problems in the Age of Malthus. London: Frank Cass; 1967

4. Omran AR. Epidemiologic transition in the U.S.; the health factor in population change. Pop Bull 1977; 32: 3-42

5. Caselli G. Health transition and cause-specific mortality. In: R. Schofield, D. Reher, A. Bideau, eds. The Decline in Mortality in Europe. Oxford: Clarendon Press; 1991.

6. Mackenbach JP. De epidemiologische transitie in Nederland. Nederlands Tijdschrift voor Geneeskunde 1993; 137: 132-138.

7. Mackenbach JP. De achtergronden van de sterftedaling tussen $1875 / 79$ en 1970 in Nederland. Tijdschrift Sociale Gezondheidszorg 1993; 71 : $192-197$

8. Mercer AJ. Smallpox and epidemiological-demographic change in Europe: The role of vaccination. Pop Studies 1985; 39: 287-307.

9. Razzell PE. An interpretation of the modern rise of population in Europe-A critique. Pop Studies 1974; 28: 5-17.

10. Mackenbach JP, Looman CWN. Secular trends in infections disease mortality in The Netherlands: Quantitative estimates of changes coin ciding with the introduction of antibiotics. Int J Epidemiol 1988; 17 618-624

11. Mercer A. Disease, Mortality and Population in Transition. Leicester, UK: Leicester University Press; 1990.

12. Berry B, Malt RA. Appendicitis near its centenary. Annals Surg 1984 200: 567-575.

13. Becker WF, Powell JL, Turner RJ. A clinical study of 1060 patients with acute cholecystitis. Surg Gynaecol Obstet 1957; 104: 491-496.

14. Cohn I. Intestinal obstruction. In: Bockus HL, ed. Gastroenterology, Vol. 2, 3rd ed. Philadelphia: Saunders; 1976.

15. Butler NR, Alherman ED. Perinatal Prohlems: the Second Report of the 1958 British Perinatal Mortality Survey. Edinburgh: Livingstone; 1958 
16. Szreter S. The importance of social intervention in Britain's mortality decline c. 1850-1914. J Social History Med 1988; 1: 1-37.

17. Hofstee EW. De Demografische Ontwikkeling van Nederland in de Eerste Helft van de Negentiende Eeuw. Deventer: Van Loghum Slaterus; 1979.

18. Houwaart ES. De Hygiënisten: Artsen, Staat en Volksgezondheid in Nederland 1840-1890. Groningen: Historische Uitgeverij Groningen 1991.

19. Vogelzang 1. De Drinkwatervoorziening van Nederland voor de Aanleg van de Drinkwaterleidingen. Utrecht: Academisch Proefschrift Utrecht 1956.

20. van Zon H. Een zeer Onfrisse Geschiedenis. Studies over Niet-Industriële Vervuiling in Nederland 1850-1920. Groningen: Academisch Proefschuift Groningen, 1986.

21. Rostow WW. The World Economy: History and Prospect. London: Macmillan; 1978.

22. van Stuijvenberg JH. De economie in de Noordelijke Nederlanden 1770-1970. In: Algemene Geschiedenis der Nederlanden, deel 10. Haarlem: Van Dishoeck; 1981

23. Luckin B. Evaluating the sanitary revolution: Typhus and typhoid in London, 1851-1900. In: Woods R, Woodward J, eds. Urban Disease and Mortality in Nineteenth Century England. London: Batsford Academic and Educational; 1984.
24. Reves R. Declining fertility in England and Wales as a major cause of the twentieth century decline in mortality. Am J Epidemiol 1985; 122: $112-126$.

25. de Regt A. Arheidersgezinnen en Beschavingsarheid: Ontwikkelingen in Nederland 1870-1940. Meppel: Van Gorcum; 1984.

26. Kunitz S. Disease Change and the Role of Medicine-The Navajo Experience. Berkeley, California: University of California Press; 1983.

27. Lever AF. The role of medicine. Lancet 1977; 309; 352-355.

28. Beeson PB. McKeown's 'The role of medicine'-A clinician's reaction. Milbank Memorial Fund Q 1977; 55: 365-371.

29. Rutstein DD, Berenherg W, Chalmers TC, et al. Measuring the quality of medical care. N Engl J Med 1976; 294: 582-588

30. Mackenbach JP, Bouvier-Colle MW, Jougla E. 'Avoidable' mortality and health services. A review of aggregate data studies. J Epidemiol Community Health 1990; 44: 106-111.

31. Goldman L, Cook EF. The decline in ischaemic heart disease mortality rates. Annals Intern Med 1984; 101: 825-836.

32. Mackenbach JP, Looman CWN, Kunst AE, et al. Post-1950 mortality trends and medical care: Gains in life expectancy due to declines in mortality from conditions amenable to medical intervention. Social Sci Med 1988; 27: 889-894. 